\title{
Telomeric DNA-protein interactions of Oxytricha Macronuclear DNA
}

\author{
Carolyn M. Price and Thomas R. Cech \\ Department of Chemistry and Biochemistry, University of Colorado, Boulder, Colorado 80309
}

Telomeres of Oxytricha macronuclear chromatin exist as discrete nonnucleosomal DNA-protein complexes, each of which encompasses the terminal $100-150$ bp of a macronuclear DNA molecule. We have used chemical and nuclease footprinting to examine the internal structure of these telomeric complexes. Remarkably saltstable DNA-protein interactions result in methylation-protection of specific guanine residues in the $3^{\prime}$ '-terminal $T_{4} G_{4} T_{4} G_{4}$ tail. The methylation pattern seen in vivo and in isolated macronuclei is reconstituted in vitro when purified 55-kD and 43-kD telomere proteins are added to purified macronuclear DNA. Very different interactions are observed between protein and DNA within the region $\sim 45-135$ bp from the 5 ' terminus. The DNase I cleavage pattern indicates that this DNA lies on the outside surface of protein but is not part of a nucleosome. Our data suggest that the telomeric complexes have two structural domains characterized by their dissimilar DNA-protein interactions. We propose that functionally equivalent telomeres from other organisms could be accommodated in a similar telomeric chromatin structure.

[Key Words: Telomeres; Oxytricha; DNA-protein interactions; footprinting]

Received June 29, 1987; revised version accepted August 4, 1987.

Telomeres, the natural ends of chromosomes, have several properties that are not duplicated by the ends of broken chromosomes or linear DNA molecules in general (reviewed by Blackburn and Szostak 1984; Blackburn 1984). Telomeres stabilize the ends of chromosomes so that degradation and end-to-end joining are prevented. In addition, they make possible the complete replication of linear DNA molecules. The DNA found in nuclear telomeres from assorted unicellular and simple multicellular eukaryotes consists of tandem repeats of simple sequences that conform to the general formula $\mathrm{C}_{1-8}(\mathrm{~T} / \mathrm{A})_{1-4}$. The striking similarity between telomeric DNA sequences from widely diverse species suggests that these sequences are important for telomeric function.

Despite the conserved nature of telomeric DNA, functionally equivalent telomeres from different species can differ significantly in terminal DNA sequence and structure. For example, ribosomal DNA telomeres from Tetrahymena macronuclei consist of 20-70 repeats of the sequence $\mathrm{C}_{4} \mathrm{~A}_{2}$ and appear to end in a hairpin structure (Blackburn and Gall 1978; Greider and Blackburn 1985). In contrast, telomeric DNA from Oxytricha macronuclei consists of only 2.5 repeats of the sequence $\mathrm{C}_{4} \mathrm{~A}_{4}$ and ends in a $3^{\prime}$ single-stranded tail (Klobutcher et al. 1981). Findings such as these suggest that something more than DNA of a certain sequence and structure is required for the end of a chromosome to act as a telomere. This premise is also supported by the sensitivity of purified telomeric DNA to degradation by exonucleases (Yao and Yao 1981; Dawson and Herrick 1984).
One way that functionally equivalent telomeres might form from telomeric DNAs of varied sequence and structure is by the binding of protein to telomeric DNA to form a nucleoprotein complex. Such telomeric complexes have been identified in a number of species, including Tetrahymena, Physarum, and Oxytricha (Blackburn and Chiou 1981; Budarf and Blackburn 1986; Cheung et al. 1981; Gottschling and Cech 1984). Terminal non-nucleosomal complexes may also be present in yeast, as a protein activity has been found that binds telomeric DNA with high specificity (Berman et al. 1986). The Tetrahymena telomeric complexes are heterogeneous in size and protect the terminal 200-600 bp of DNA from nuclease digestion. Little is known about the structure and composition of these complexes. The Physarum telomeric complexes are primarily located in the region $1-2 \mathrm{kbp}$ from the extreme terminus in a region containing multiple inverted repeats and single-stranded gaps. The complexes appear to contain two covalently bound proteins. The Oxytricha nova telomeric complex protects a discrete region at the end of each macronuclear DNA molecule and has been more amenable to characterization than either the Tetrahymena or the Physarum complexes.

Both the large number of macronuclear telomeres in Oxytricha and the well-defined DNA sequence and structure of these telomeres have expedited study of the telomeric complex. The somatic macronucleus of Oxytricha contains some $24 \times 10^{6}$ gene-sized DNA molecules, which range in length from 400 to $20,000 \mathrm{bp}$ (Swanton et al. 1980b; Prescott 1983). The ends of the 
DNA molecules are characterized by the sequence:

$5^{\prime}$-CCCCAAAACCCCAAAACCCC..... 3'HO-GGGGTTTTGGGGTTTTGGGGTTTTGGGGTTTTGGGG.....

(Klobutcher et al. 1981). No additional conserved telomere-associated regions have been identified; the DNA adjacent to the $\mathrm{C}_{4} \mathrm{~A}_{4}$ repeats is unique in sequence. In isolated macronuclei a terminal region of $100-150 \mathrm{bp}$ of each DNA molecule is protected from both nuclease and chemical cleavage, providing evidence for a telomeric complex that encompasses the $3^{\prime}$ terminal $\mathrm{T}_{4} \mathrm{G}_{4}$ tail, the duplex $\mathrm{C}_{4} \mathrm{~A}_{4} \cdot \mathrm{T}_{4} \mathrm{G}_{4}$ repeats, and $80-130 \mathrm{bp}$ of adjacent DNA (Gottschling and Cech 1984). The complex is too small to be a complete nucleosome and contains nonhistone proteins. Components of the complex include a $55-\mathrm{kD}$ and a $26-\mathrm{kD}$ protein, which remain bound to telomeric DNA in $2 \mathrm{M} \mathrm{NaCl}$ (Gottschling and Zakian 1986). These proteins appear to bind noncovalently as they can be displaced by treatment with $7 \mathrm{M}$ urea, phenol, alkaline $\mathrm{pH}$, and temperatures $>55^{\circ} \mathrm{C}$. Mixtures of the two proteins bind Oxytricha telomeric DNA in vitro, showing specificity for the $3^{\prime}$ tail and, to a lesser extent, the duplex $\mathrm{C}_{4} \mathrm{~A}_{4} \cdot \mathrm{T}_{4} \mathrm{G}_{4}$ region (Gottschling and Zakian 1986). Whether the native telomeric complex contains additional protein or nonprotein components remains to be determined.

In the present study we have used both chemical and nuclease footprinting to examine the internal structure of the telomeric complex in living cells and in isolated macronuclei. We have shown that the DNA-protein interactions within the complex result in an ordered nucleoprotein particle that is structurally quite different from a nucleosome. We have also shown that binding of the $55-\mathrm{kD}$ and the $43-\mathrm{kD}$ telomere proteins to macronuclear DNA in vitro reconstitutes some of the DNA-protein interactions that are present in the telomeric complex in vivo. Studies using Oxytricha are providing the first detailed information about the chromatin structure of telomeres.

\section{Results}

Detection of DNA-protein interactions within the telomeric complex using dimethyl sulfate

Accessibility of guanine (G) residues in the terminal $\mathrm{T}_{4} \mathrm{G}_{4}$ repeats within the telomeric complex was probed with the methylating reagent dimethyl sulfate (DMS) (Gilbert et al. 1976; Siebenlist and Gilbert 1980). Either live Oxytricha or isolated macronuclei were treated with DMS as described in Experimental procedures. The DNA was then isolated, $3^{\prime}$ end-labeled, cleaved at the 7-methylguanine adducts using piperidine, and analyzed by electrophoresis on sequencing gels. Figure 1A shows the pattern of $G$ methylation obtained with living cells and with isolated macronuclei. The pattern obtained when deproteinized macronuclear DNA was treated with DMS is also shown. Strong methylation-protection (marked *) is apparent at six G residues within the telomeric complexes from both living cells and isolated macronuclei. As illustrated in Figure 1C, these six bases are part of the 3' tail. The extent of $G$ methylation in the duplex region is similar for the telomeric complexes and the deproteinized DNA.

Control samples that were not exposed to DMS show a low level of cleavage at $G$ residues (e.g., control lanes $10-40$ ). This background cleavage is caused by the piperidine treatment (Johnson and Rich 1985); it does not increase with time, and the extent of cleavage is very much lower than that of the G cleavage resulting from DMS methylation. Methylation-protection is lost when macronuclei are treated with proteinase $\mathrm{K}$ and $0.5 \%$ SDS prior to DMS treatment (control lane P). This demonstrates that methylation-protection is caused by interaction of protein with DNA.

Our data indicate that some protein within the telomeric complex interacts closely and in a sequence-specific manner with the $3^{\prime}$ tail of the telomeric DNA. As the experiments were performed with both living cells and isolated macronuclei, we have identified the interactions that occur in vivo, and we have shown that these interactions are not disrupted during macronuclear isolation. Although Oxytricha remain viable in $5 \mathrm{~mm}$ DMS for only a little over $10 \mathrm{~min}$, some methylation-protection is observed after only $1 \mathrm{~min}$. At this time cellular structure does not appear to be greatly disrupted, because Oxytricha removed from DMS after a 1-min exposure remain alive for at least $24 \mathrm{hr}$. The prolonged DMS treatment made possible by using macronuclei allows methylation-protection to be seen more clearly and shows that the interactions causing the protection pattern are quite stable to DMS.

The DNA-protein interactions responsible for methylation-protection appear to be largely nonelectrostatic in nature, as the protection pattern is essentially unaffected by salt concentration. Suspension of macronuclei in Tris/ $\mathrm{NaCl}$ buffers ranging from 0 to $2 \mathrm{M} \mathrm{NaCl}$ just prior to DMS treatment does not alter the resultant methylation-protection pattern (Fig. 1B). Although the general efficiency of DMS methylation in the $3^{\prime}$ tail is somewhat reduced by $1-2 \mathrm{M} \mathrm{NaCl}$, each $\mathrm{G}$ residue is affected to the same extent, so that the presence or absence of methylation-protection is not masked.

It is apparent from Figure 1 that the repeated runs of four $G$ residues do not stop completely at the end of the 20-bp $\mathrm{C}_{4} \mathrm{~A}_{4} \cdot \mathrm{T}_{4} \mathrm{G}_{4}$ tract but extend further in some fraction of the macronuclear DNA molecules. Cleavage at thymine (T) residues (Maxam and Gilbert 1977, 1980) indicates that groups of four $\mathrm{T}$ residues alternate with groups of four $\mathrm{G}$ residues in this region (data not shown). It is possible that the extended pattern of $\mathrm{G}_{4} \mathrm{~T}_{4}$ repeats results from some molecules having unusually long stretches of telomeric DNA. Alternatively, the repeated pattern could reflect an overall $\mathrm{G}_{4} \mathrm{~T}_{4}$ consensus sequence internal to the telomeric region. However, the limited number of macronuclear genes that have been sequenced (Klobutcher et al. 1984; Ribas-Aparicio et al. 1987; A. Greslin and D. Prescott, pers. comm.) show no tendency toward continuation of the $\mathrm{G}_{4} \mathrm{~T}_{4}$ sequence internal to the canonical 6.5 repeats.

\section{DNase I footprinting of the telomeric complex}

The accessibility of DNA within the telomeric complex was examined using the nuclease DNase I. Isolated ma- 


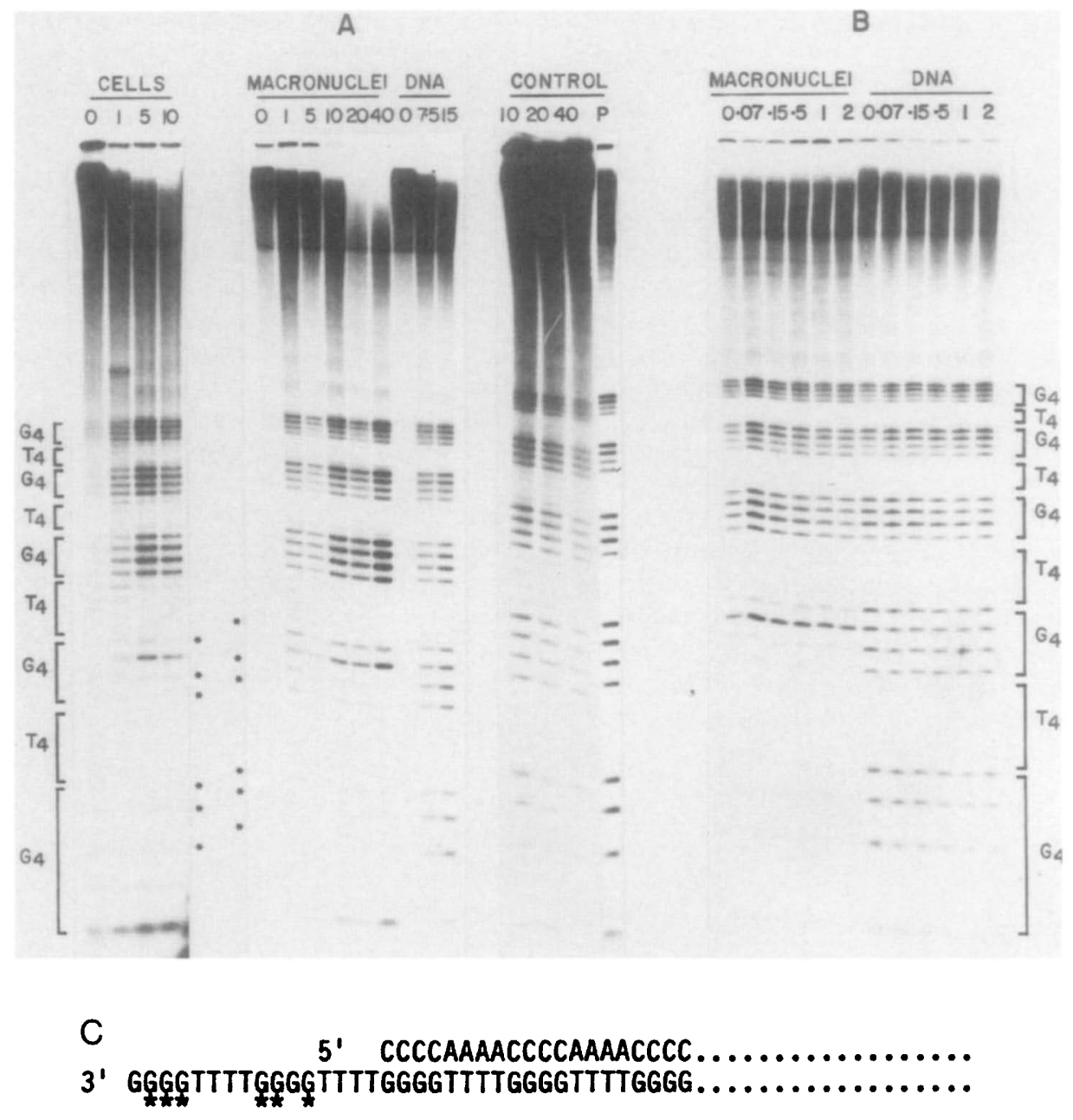

Figure 1. Specific guanine residues in the telomeric DNA-protein complex are protected from methylation. Deproteinized DNA, living cells, and isolated macronuclei were methylated with DMS. Following purification, the DNA was 3' end-labeled, cleaved at the methylated G residues, electrophoresed on sequencing gels, and exposed to film. The sequence of the DNA is shown at the extreme right and left. G residues exhibiting methylation protection are marked *. $|A|$ The DMS methylation pattern obtained with DNA from living cells and macronuclei and with deproteinized DNA. The duration of the DMS treatment is shown, in minutes, at the top of each lane. The control lanes 10-40 show the amount of G cleavage obtained with macronuclei incubated for 10, 20, and 40 min at $25^{\circ} \mathrm{C}$ in the absence of DMS. The control lane $P$ shows the methylation pattern obtained when macronuclei are treated with proteinase $\mathrm{K}$ and $0.5 \%$ SDS prior to DMS treatment. $(B)$ The DMS methylation pattern obtained with macronuclei or deproteinized DNA in the presence of increasing concentrations of $\mathrm{NaCl}$. The molar concentration of $\mathrm{NaCl}$ present during DMS treatment is shown at the top of each lane. $(C)$ Summary of the data shown in $A$ illustrating the position of the protected $G$ residues relative to the structure of the telomeric DNA. Protected G residues are marked *.

cronuclei were digested with DNase I, and the DNA was isolated and electrophoresed on polyacrylamide gels. To examine only the telomeric DNA, the DNA in these gels was transferred to nylon membrane and the telomeric DNA was indirectly end-labeled by hybridization with the ${ }^{32} \mathrm{P}$-labeled synthetic oligonucleotide $\left(\mathrm{G}_{4} \mathrm{~T}_{4}\right)_{2}$. Because this probe hybridizes to the $\mathrm{C}_{4} \mathrm{~A}_{4}$ repeats at the $5^{\prime}$ end of the telomeric DNA, no information was obtained about the DNase I accessibility of the 3 '-terminal $\mathrm{T}_{4} \mathrm{G}_{4}$ tail. As shown in Figure 2A, a stretch of telomeric DNA was cleaved by DNase I in a highly repetitive manner. Within the region extending from $\sim 45 \mathrm{bp}$ to $\sim 140$ bp from the $5^{\prime}$ terminus, the DNA was cut at 8 - to 12-base intervals. The most terminal 45 bp of DNA gave a discrete but irregular pattern of cleavage. DNase I digestion of deproteinized macronuclear DNA yielded no discrete digestion pattern aside from a small amount of sequence-specific cleavage near the terminus. In analogous experiments performed with DNase II, similar repetitive digestion patterns were obtained (D. McGarvy and C. Price, unpubl. results). In these experiments, both EDTA and magnesium-containing buffers were used.

Treatment of macronuclei with $2 \mathrm{M} \mathrm{NaCl}$ destroys the telomeric structure responsible for the repetitive digestion pattern (data not shown). As DNase I is inactive in high salt, macronuclei were treated with $2 \mathrm{M} \mathrm{NaCl}$, the dissociated proteins were separated from the macronuclear DNA by gel filtration, and the salt was removed by dialysis. The structure of the residual telomeric complexes was then probed with DNase I as described above.

The repetitive portion of the digestion pattern shown in Figure 2A has a periodicity similar to the pattern ob- 
tained when DNA in nucleosomes is digested with DNase I (Fig. 2B, lane 1). The 10.4-bp periodicity of the nucleosomal digestion pattern (Noll 1974; Prunell et al. 1979) arises from the passage of the nucleosomal DNA around the outside of the histone octamer (Klug and Lutter 1981). To ascertain whether the telomeric DNA might be involved in similar DNA-protein interactions, the periodicity of the DNase I digestion pattern from the telomeric complex was determined accurately.

DNA from DNase I-digested macronuclei was electrophoresed in high-resolution polyacrylamide gels that allowed mixed-sequence DNA to be separated solely on the basis of size (Lutter 1979). The DNA was then electroblotted to nylon membrane and hybridized to the $\left(\mathrm{G}_{4} \mathrm{~T}_{4}\right)_{2}$ probe. DNA fragments differing in size by a single nucleotide were resolved, and the repeating pattern caused by the DNase I digestion was visible. Figure $3 \mathrm{~A}$ shows densitometric scans of autoradiograms from two gels. The scans demonstrate that maxima of DNase I cleavage occur every $10-11$ bases within the region $\sim 48-132$ bp from the $5^{\prime}$ terminus. The average periodicity of cleavage was $10.27 \pm 0.06$ bases (Fig. 3B). The ac- tual error may be greater, as both electrotransfer of DNA to nylon membrane and hybridization with probe can occur somewhat unevenly. The cleavage periodicity of 10.27 is similar to the 10.4-bp periodicity of DNase I cleavage of DNA within a nucleosome (Lutter 1979), the 10- to 11-bp periodicity of cleavage within the DNADNA gyrase complex (Liu and Wang 1978), and the 10.6bp periodicity of cleavage of DNA lying on a flat inorganic surface (Liu and Wang 1978; Rhodes and Klug 1980). Thus, it appears that at least $84 \mathrm{bp}$ of the Oxytricha telomeric DNA lie on the outside of a protein surface.

To compare further the DNA-protein interactions present in telomeric complexes and nucleosomes, we examined the relative frequency of DNase I cleavage at each of the cleavage maxima in the two types of complex. In the telomeric complexes there are nine cleavage maxima. These are cut by DNase I with fairly even frequency, although, on average, the sites around 79 and 90 bp are cut slightly more often than the other sites (Fig. 2A). The sites around 48 and 59 bp have an apparently lower frequency of cleavage in some experiments (com-

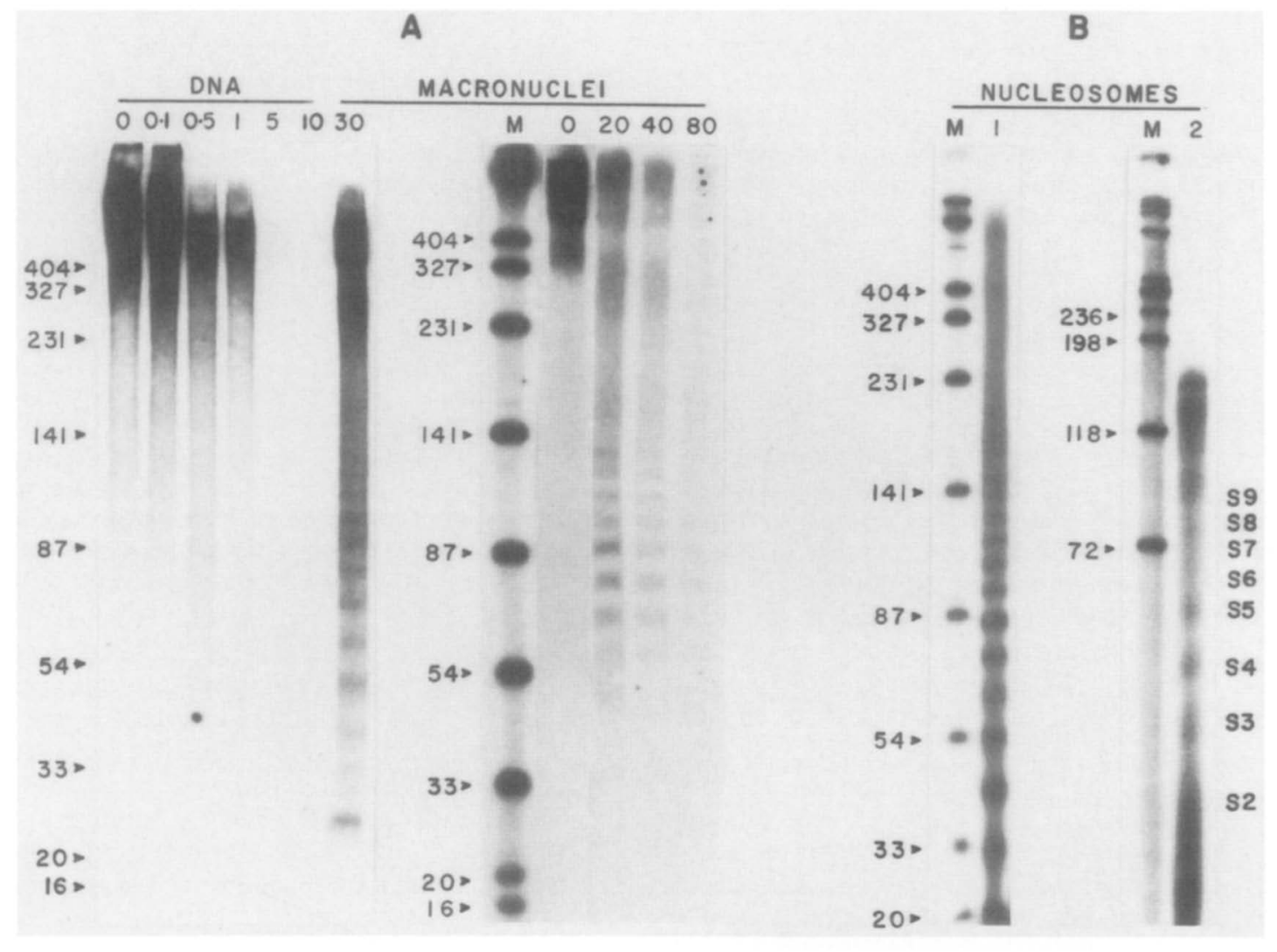

Figure 2. DNase I digestion of Oxytricha telomeric complexes and Oxytricha nucleosomes. Oxytricha macronuclei, deproteinized macronuclear DNA, or isolated nucleosomes were digested with DNase I. The DNA was isolated and electrophoresed on denaturing $6 \%$ polyacrylamide gels. (A) Southern blots of DNase I-digested macronuclei and deproteinized macronuclear DNA probed with ${ }^{32} \mathrm{P}$-labeled $\left(\mathrm{G}_{4} \mathrm{~T}_{4}\right)_{2}$. Because the DNA is indirectly end-labeled, the relative intensity of each band is proportional to the frequency of DNase I cleavage at that site. The amount of DNase I used per digestion is shown above each lane $(\mathrm{K}$ units $/ \mathrm{ml}) .(B) \mathrm{DNase} \mathrm{I}-$ digested macronuclear chromatin and isolated nucleosomes. (Lane 1); DNase I-digested macronuclear chromatin; the DNA was 5 '-end-labeled after DNase I digestion. (Lane 2) DNase I-digested nucleosomes; the DNA was 5 '-end-labeled while it was in nucleosomes, prior to DNase I digestion. The relative intensity of each band is proportional to the frequency of cleavage at that site. S2-S9 indicate the main sites of DNase I cleavage within the nucleosomes. In $A$ and $B$, lanes $M$ contain marker DNA. The sizes (in bases) of the markers are indicated to the left of each panel. 
B
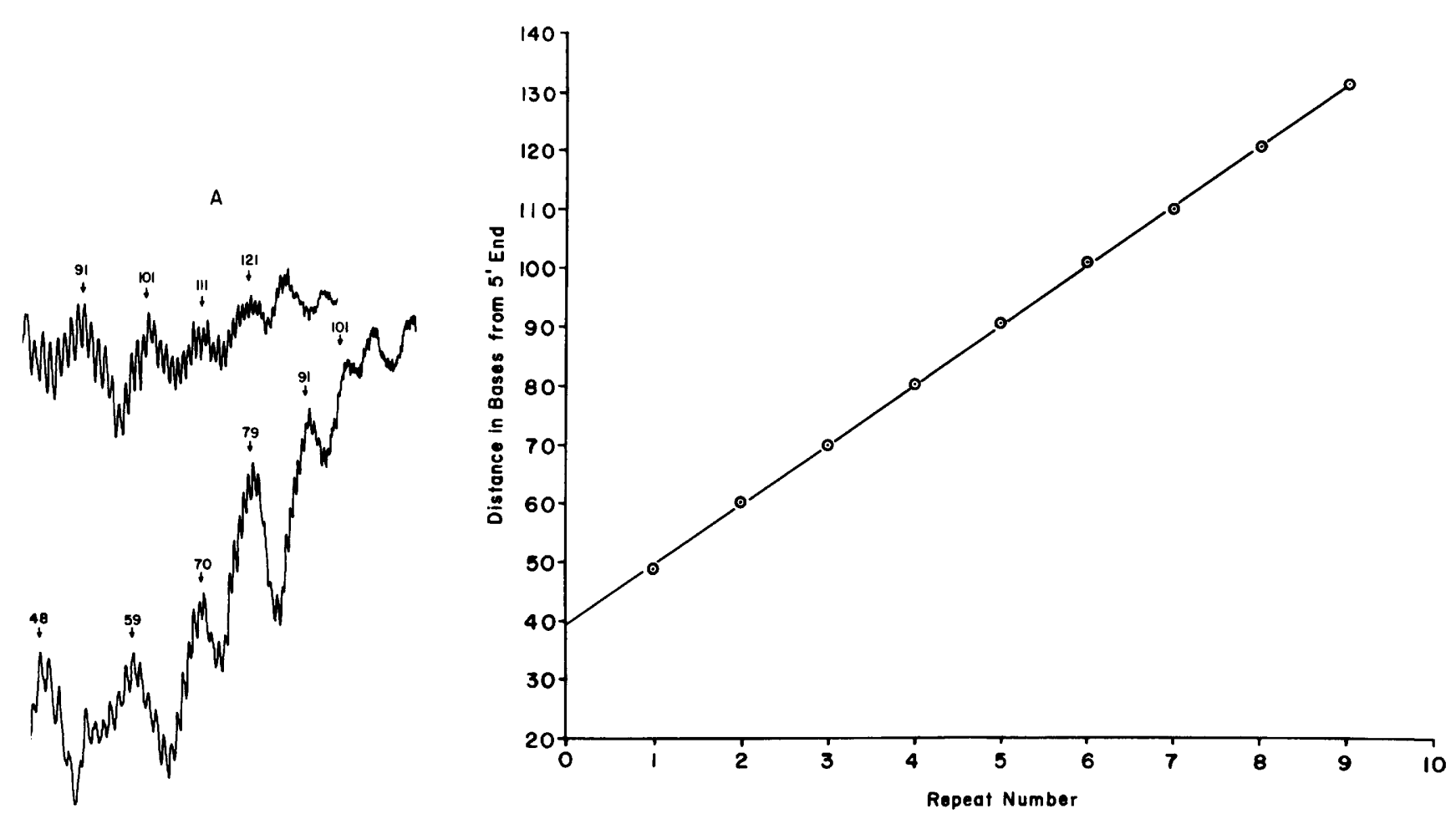

Figure 3. The periodicity of DNase I cleavage within the Oxytricha telomeric complex. Oxytricha macronuclei were digested with DNase I, and the DNA was isolated and electrophoresed on high-resolution polyacrylamide gels. The DNA was transferred to nylon membrane and the telomeric DNA was indirectly end-labeled by hybridization with ${ }^{32} \mathrm{P}-\mathrm{labeled}\left(\mathrm{G}_{4} \mathrm{~T}_{4}\right)_{2}$. $(A)$ Densitometric scans of an autoradiogram showing the periodicity of DNase I cleavage within the Oxytricha telomeric complex. The sizes of the DNA found at sites of maximal cleavage are marked. $(B)$ The sites of maximal DNase I cleavage were determined from densitometric scans similar to those shown in $A$ and plotted against the repeat number. The line drawn through the points is a least-squares fit of the data from three separate experiments. The slope has a value of $10.27 \pm 0.06$ (mean $\pm \mathrm{SD}$ ) bases/repeat.

pare Fig. 2A, macronuclei fanes 30 and 20), but this appears to be caused by variable efficiency in the binding of smaller DNA fragments to the nylon blotting membrane. In nucleosomes, there are 14 sites of maximal DNase I cleavage (S1-S14), which are attacked by DNase I with very different frequency (Simpson and Whitlock 1976; Lutter 1978). That this general observation holds true for Oxytricha nucleosomes is demonstrated in Figure 2B, lane 2. This figure illustrates the different frequency of DNase I cleavage at sites 2-9 within Oxytricha nucleosomes. Although the mononucleosome preparation contained DNA that was rather heterogeneous in length, it is still apparent that sites 4 and 5 have been cleaved with much greater frequency than sites 6-8 (Lutter 1978; Cockell et al. 1983). As will be discussed later, the differences in frequency of DNase I cutting within telomeric complexes and nucleosomes indicate that telomeric complexes are unlikely to contain either a complete or a partial nucleosome.

\section{In vitro reconstitution of telomeric nucleoprotein complexes}

Nucleoprotein complexes were assembled using purified macronuclear DNA and two telomere-associated pro- teins; the DMS methylation pattern of the DNA in the complex was then examined. The telomere proteins used in these experiments were the previously identified 55-kD protein (Lipps et al. 1982; Gottschling and Zakian 1986) and a larger form of the $26-\mathrm{kD}$ protein described by Gottschling and Zakian (1986). The proteins were isolated essentially as described by Gottschling and Zakian (1986), except that additional protease inhibitors were used. Two-molar $\mathrm{NaCl}$ was used to dissociate all proteins, except the two telomere-associated proteins, from the macronuclear DNA. Both telomere proteins were then released from the DNA by digestion of the DNA by micrococcal nuclease. Attempts to separate the two proteins using nondenaturing conditions have as yet been unsuccessful.

Inclusion of the protease inhibitors phenylmethanesulfonyl fluoride (PMSF), tosylphenylalanine chloromethylketone (TPCK), and p-chloromercuribenzenesulphonic acid (PCMBS) during macronuclear isolation and of PMSF and TPCK during the subsequent protein purification resulted in the isolation of a $43-\mathrm{kD}$ protein instead of a $26-\mathrm{kD}$ protein (Fig. $4 \mathrm{~A}$ ). The $43-\mathrm{kD}$ protein was recognized by antibodies to the $26-\mathrm{kD}$ protein (antibodies provided by Gottschling and Zakian). Figure 4B 


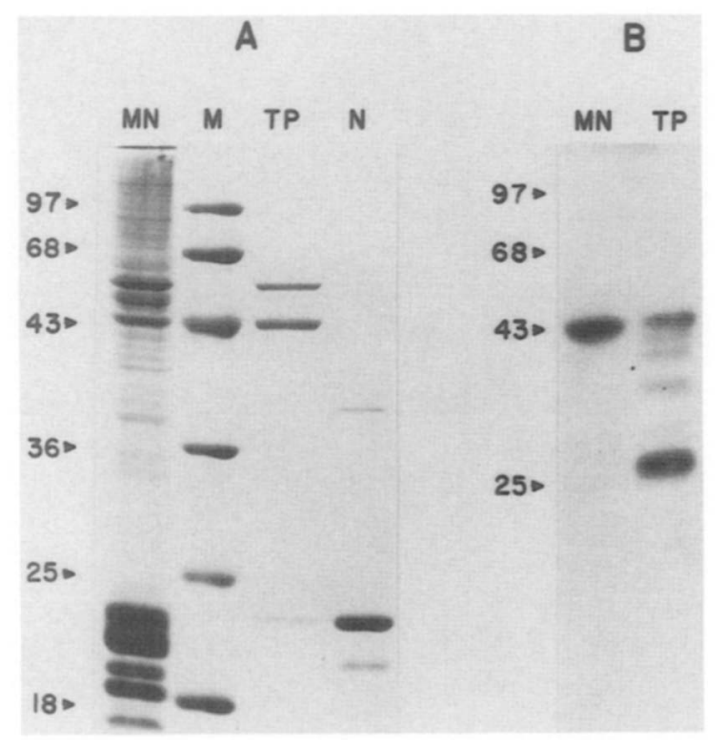

Figure 4. Isolation of the $55-\mathrm{kD}$ and $43-\mathrm{kD}$ telomere proteins. (A) Coomassie Blue-stained SDS polyacrylamide gel showing total Oxytricha macronuclear proteins (lane $M N$ ), isolated telomere proteins (lane $T P$ ), and micrococcal nuclease (lane N). Molecular weights of marker proteins (lane $M$ ) are given in kilodaltons at the extreme left. (B) An immunoblot of an SDS polyacrylamide gel probed with antibodies to the previously identified 26-kD telomere protein. Lane $M N$ contains total $O X-$ ytricha macronuclear proteins, lane $T P$ contains isolated telomere proteins. The positions and molecular weights of marker proteins run on the same gel are indicated at the left.

shows an immunoblot probed with antibodies to the $26-\mathrm{kD}$ protein. Lane $\mathrm{Tp}$ shows a partially degraded preparation of the telomere proteins (isolated from a rather degraded total-macronuclear-protein extract) in which 43- and $26-\mathrm{kD}$ bands as well as intermediate-sized fragments are apparent. We conclude that the $26-\mathrm{kD}$ protein is a degradation product of the $43-\mathrm{kD}$ protein.

As shown in Figure 5, incubation of $3^{\prime}$ end-labeled macronuclear DNA with increasing amounts of the telomere protein preparation prior to DMS treatment results in restoration of methylation-protection. The protection pattern is similar to that seen when living cells or isolated macronuclei are treated with DMS (Fig. 6), although the second, third, and fourth $G$ residues are protected somewhat less in the reconstituted complexes. Assembly of complexes using DNA that is not $3^{\prime}$ end-labeled also results in restoration of methylationprotection (data not shown). Protection is not observed if proteinase $\mathrm{K}$ is added to the telomere proteins either prior to their incubation with macronuclear DNA or after formation of the nucleoprotein complex (Fig. 5, lanes P1 and P2). Although the nucleoprotein complexes assembled in vitro do contain some of the DNA-protein interactions found in vivo, the full structure of the native telomeric complex is not reformed. Using conditions that give reconstitution of chicken nucleosomes (Simpson et al. 1985), it was not possible to reform the structure that gives rise to the 10.27-bp repeat pattern upon DNase I digestion of native telomeric complexes (data not shown).
It appears that the $55-$ and $43-\mathrm{kD}$ proteins alone are sufficient to give methylation protection. The gel shown in Figure 4A shows that, aside from micrococcal nuclease, contaminant proteins are present in only trace amounts. Micrococcal nuclease does not give rise to methylation protection when incubated with macronuclear DNA in the absence of calcium (Fig. 5, lane M). The molar ratio of telomere proteins to DNA that gives maximal methylation protection is approximately $2: 1$

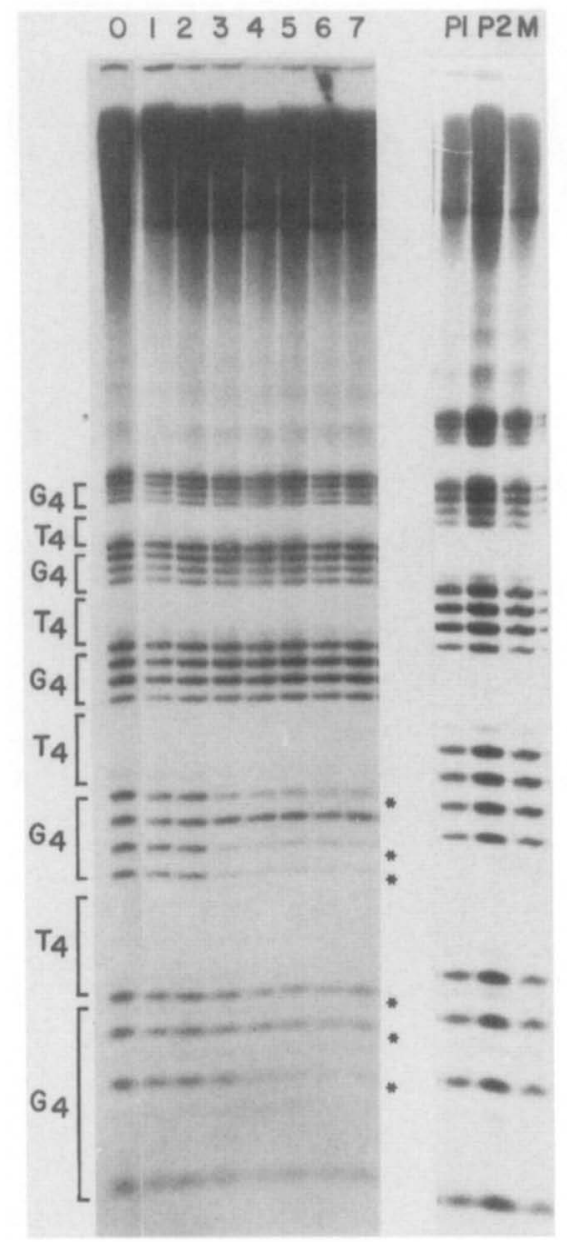

Figure 5. Protection of guanine residues in the telomeric DNA upon reconstitution of nucleoprotein complexes. Nucleoprotein complexes were formed from 3'-end-labeled macronuclear DNA plus the $55-\mathrm{kD}$ and $43-\mathrm{kD}$ telomere proteins. The complexes were treated with DMS and the DNA isolated, cleaved at the methylated $\mathrm{G}$ residues, and electrophoresed on sequencing gels. The sequence of the DNA is shown at the extreme left. G residues exhibiting methylation-protection are marked *. Lanes 0-6 contain a pmole : pmole ratio of DNA to $55-\mathrm{kD}$ telomere protein of approximately $1: 0,1: 0.3,1: 0.7,1: 1.3,1: 2.6$, $1: 3.9$, and $1: 5.3$ in the reconstitution mixture. The amount of $43-\mathrm{kD}$ telomere protein in samples $1-6$ was roughly one-third the amount of $55-\mathrm{kD}$ telomere protein. Lanes $P 1$ and $P 2$ had the same ratio of DNA to telomere protein in the reconstitution mixture as lane 5 ; however, the telomere proteins were treated with proteinase $\mathrm{K}$ prior to addition of the DNA (P1) or after reconstitution of the complex $(P 2)$. Lane $M$ shows the methylation pattern obtained when micrococcal nuclease (in the absence of calcium) was substituted for the telomere proteins during reconstitution. 

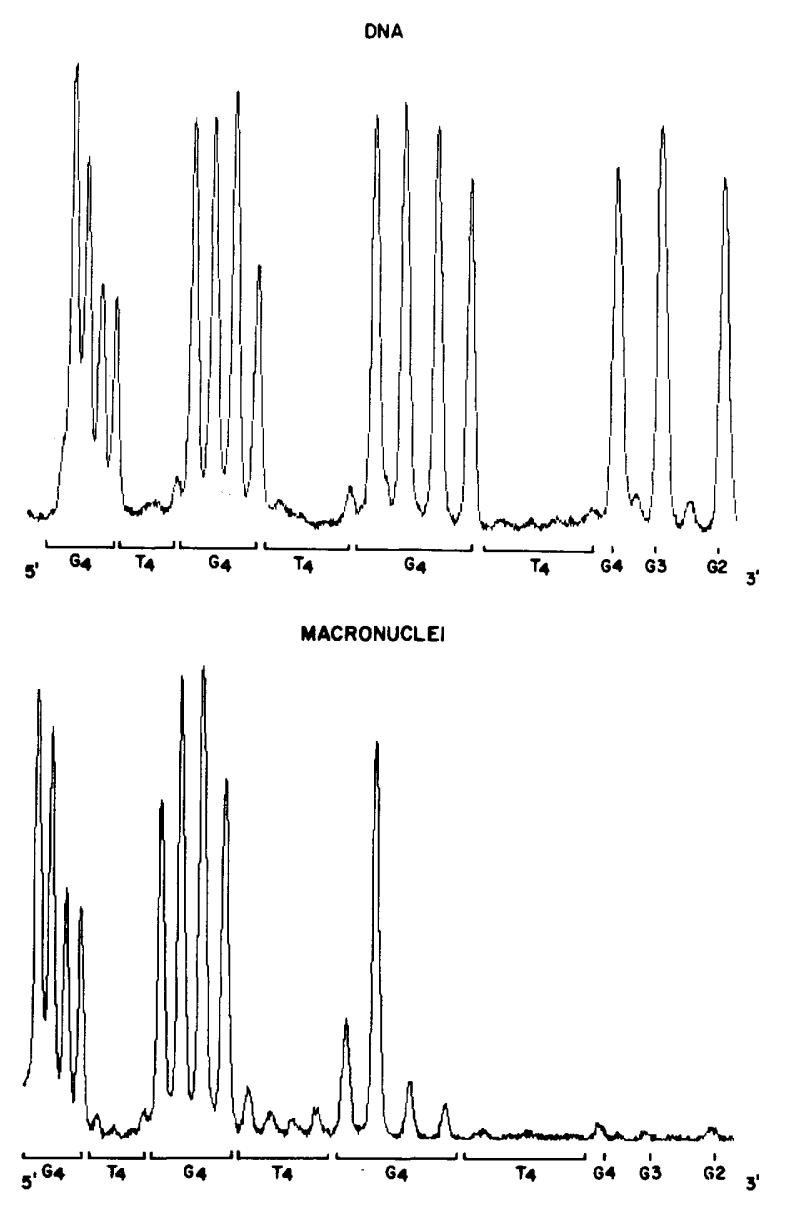

RECONSTITUTED COMPLEXES

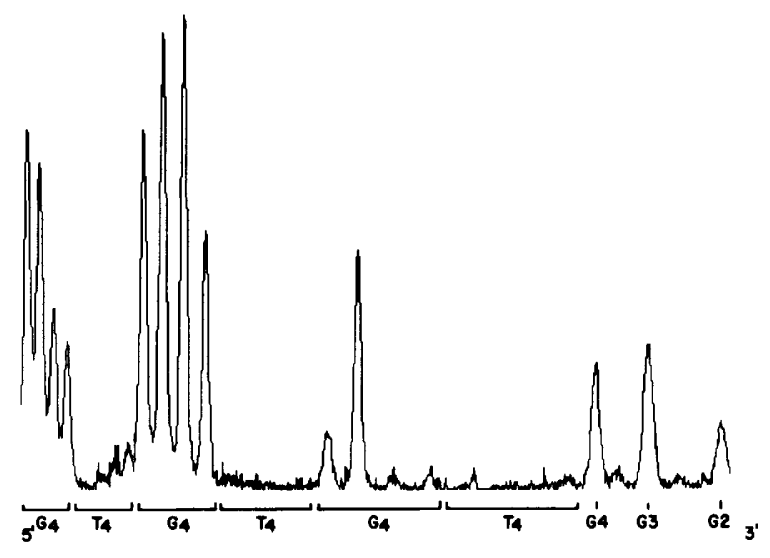

Figure 6. Comparison of the methylation-protection pattern obtained upon DMS treatment of deproteinized DNA, macronuclei, and reconstituted telomeric nucleoprotein complexes. Autoradiograms similar to those shown in Figs. 1 and 5 were scanned with a Hoeffer densitometer. The sequence of the DNA is illustrated below each scan. The peak heights are proportional to the intensity of the bands on the autoradiogram.

for the $55-\mathrm{kD}$ protein and $<1: 1$ for the $43-\mathrm{kD}$ protein (details of this estimation are given in Experimental procedures). Thus, it seems unlikely that any additional protein is present in sufficient quantity to be a stoichiometric component of the reconstituted nucleoprotein particle.
Although the preparations of telomere proteins are treated with micrococcal nuclease, it remains possible that RNA in the form of a ribonucleoprotein particle might be present and be required to give methylation protection. This is unlikely to be the case because when the telomere protein preparations are denatured and run on denaturing acrylamide gels, no RNA is observed upon ethidium bromide staining (data not shown). Sufficient protein was loaded on these gels to yield approximately $0.6 \mu \mathrm{g}$ of any 100-nucleotide RNA molecule present in the protein preparations in stoichiometric amounts.

\section{Discussion}

Results from past research exemplify the need to characterize the nucleoprotein structure of telomeres so that we may comprehend how telomeres perform their various roles in cells. For example, once the DNA-protein interactions at the terminus of the adenovirus genome were characterized, the mechanisms of adenovirus replication became much better understood (for review, see Campbell 1986). Studies of telomere structure using the ciliate Oxytricha nova are providing the first detailed picture of the type of DNA-protein interactions that occur at nonviral telomeres. Gottschling and Cech (1984) originally demonstrated the presence of a telomeric nucleoprotein complex that appeared to be too small to be a nucleosome. Gottschling and Zakian (1986) later identified two nonhistone proteins that are bound to Oxytricha telomeric DNA. In this article, we have examined the internal structure of the telomeric complex. The results lead us to suggest that the telomeric complex consists of two domains which are characterized by their dissimilar DNA-protein interactions. In one domain, sequence-specific protection of certain guanine residues in the DNA results from binding of the telomere proteins identified by Gottschling and Zakian (1986). In the other domain, the DNA-protein interactions are rather uniform along the length of the DNA and are largely or entirely sequence independent.

The most terminal domain encompasses the 3 '-terminal $\mathrm{T}_{4} \mathrm{G}_{4} \mathrm{~T}_{4} \mathrm{G}_{4}$ tail and roughly $45 \mathrm{bp}$ of the adjacent duplex DNA. The DNA within this domain is bound tightly by protein so that $G$ residues in the $3^{\prime}$ tail are protected from methylation in a salt-independent manner. Although the salt stability of this DNA-protein interaction is unusual, it is not without precedent. The E. coli single-stranded DNA-binding protein will bind DNA in $5 \mathrm{M} \mathrm{NaCl}$ (Lohman and Overman 1985). One possible physical basis for the salt insensitivity of the telomeric DNA-protein complex would be hydrophobic interactions. The methyl groups on the runs of Ts in the terminal $T_{4} G_{4} T_{4} G_{4}$ tail are interesting candidates for such interactions. Alternatively or in addition, protection of N-7 of Gs from methylation in the terminal complex might reflect protein-induced DNA hydrogen-bonding interactions that would be stabilized by high salt.

The proteins that bind within the terminal domain and cause methylation-protection of the $3^{\prime}$ tail are the $55-\mathrm{kD}$ protein and a larger form of the $26-\mathrm{kD}$ protein de- 
scribed by Gottschling and Zakian (1986). The 26-kD telomere protein appears to be a proteolytic fragment of a $43-\mathrm{kD}$ protein, a possibility already mentioned by Gottschling and Zakian (1986). It seems likely that methylation-protection is caused by the $55-\mathrm{kD}$ protein rather than the $43-\mathrm{kD}$ protein, because maximal methylation protection can be attained with less than a $1: 1$ molar ratio of $43-\mathrm{kD}$ protein to DNA. However, determination of the relative contributions of the $55-\mathrm{kD}$ and $43-\mathrm{kD}$ proteins to complex formation must await separation of the two proteins using nondenaturing conditions. Although nitrocellulose filter-binding assays show that the $55-\mathrm{kD}$ protein will bind to telomeric DNA following isolation of the protein from SDS gels and renaturation (Gottschling and Zakian 1986), we were unable to obtain methylation protection using denatured and renatured telomere proteins. This phenomenon appears to arise from inadequate protein renaturation rather than loss of some additional factor originally present in the protein preparation, as protection was not obtained even when the whole telomere protein preparation was denatured and renatured.

The largest and more internal domain of the telomeric complex encompasses over half the DNA found in the complex. Although the 85-90 bp of DNA within this second domain lie on the outside of a protein surface, several lines of evidence indicate that this DNA is unlikely to be part of a nucleosome. As already mentioned, the whole telomeric complex protects significantly less DNA from nuclease and chemical cleavage than would be expected if a complete nucleosome were present. Oxytricha macronuclear nucleosomes appear to have a normal core particle composition and structure and a rather long linker region of $\sim 75$ bp (Lawn et al. 1977; Butler et al. 1984). Thus, even if a nucleosome and the $55-\mathrm{kD}$ and $43-\mathrm{kD}$ telomere proteins could bind the telomeric DNA simultaneously (Rhodes 1985), one would expect to see up to $220 \mathrm{bp}$ of DNA protected from micrococcal nuclease and accumulation of 146 -bp core particles upon extensive digestion. In fact, only about 100 $\mathrm{bp}$ are protected from micrococcal nuclease (Gottschling and Cech 1984). Upon prolonged digestion there is no accumulation of protected complexes; instead, the telomeric DNA gradually diminishes in size (C. Price, unpubl. observations).

Only $\sim 75 \mathrm{bp}$ of DNA are required to complete one turn around a histone octamer. Thus, $85-90 \mathrm{bp}$ of telomeric DNA might make a little over one turn around a histone octamer and so form a partial nucleosome. Although our data do not rule out the presence of histone proteins within the telomeric complex, they do indicate that the DNA-histone interactions that normally occur when DNA wraps around a histone octamer are not present. The evidence for this is twofold. First, the telomeric complexes are much more sensitive to prolonged micrococcal nuclease digestion than are nucleosomes, suggesting that the DNA-protein interactions within the telomeric complexes are less substantial than those within nucleosomes. Second, accessibility to DNase I of DNA within telomeric complexes and nucleosomes is quite different. Although DNase I cleaves roughly every
10.5 bp within both types of complex, the relative frequency of cleavage at the nine cleavage maxima within telomeric complexes does not correspond to the relative frequency of cleavage at any nine consecutive cleavage maxima within nucleosomes. For example, within nucleosomes, sites 3,6 , and 8 are greatly protected from DNase I cleavage (Simpson and Whitlock 1976; Lutter 1978). This protection results from specific DNA-histone interactions (Richmond et al. 1984). There is no corresponding protection of cleavage maxima within the telomeric complexes.

DNA within the second telomeric domain is complex in sequence, suggesting that interaction with protein may be via the sugar-phosphate backbone. Support for this premise comes from the sensitivity of the interactions to high salt. However, if any as yet unidentified consensus sequence exists in this region, some sequence-specific contacts might also occur.

Although nucleosomes reconstituted in vitro give the characteristic 10.4-bp repeat pattern upon digestion with DNase I (Simpson and Stafford 1983), the 10.27-bp repeat pattern characteristic of the native telomeric complex is not reconstituted using the components and conditions described here. This observation suggests that native telomeric complexes may contain additional, as yet unidentified proteins. The salt sensitivity of the DNA-protein interactions within the second domain indicates that such proteins might be dissociated by the $2 \mathrm{M} \mathrm{NaCl}$ treatment which is an integral part of the telomere protein isolation procedure.

The organization of the telomeric complex gives some insight into how Oxytricha telomeres fulfill their various roles within cells. The stability of the telomeres to degradation and joining reactions is explained by the tight binding of protein to the 3' DNA tail (Gottschling and Zakian 1986). Perhaps complete replication of the terminus of the linear macronuclear DNA molecules is somehow achieved as a result of these same DNA-protein interactions. At the same time, DNA replication requires that the immediately adjacent DNA be freely accessible to DNA polymerase. Accessibility of this region to polymerase molecules is also required during transcription, since some macronuclear genes have their transcription start sites within $100 \mathrm{bp}$ of the terminus (Klobutcher et al. 1984). This accessibility to polymerases is achieved by having a more open "nucleosome-like" nucleoprotein structure within the second domain of the telomeric complex. The existence of two structural domains within the complex reflects the need to simultaneously accommodate very different DNAprotein binding requirements within one functional unit.

The macronuclear telomeres of Oxytricha and other hypotrichous ciliates are somewhat unusual in that they contain a small, well-defined number of DNA sequence repeats (Klobutcher et al. 1981; Prescott 1983), and in Oxytricha they form nucleoprotein complexes of discrete size. All other eukaryotes that have been examined have telomeres that contain larger and more variable numbers of DNA sequence repeats (Blackburn and Szostak 1984). The existing data indicate that these 
same organisms have telomeric nucleoprotein complexes that are heterogeneous in size. Such heterogeneous complexes could still have the general chromatin structure described above. The sequence and structure of the terminal DNA could be recognized and bound by a terminus-binding protein to give a nucleoprotein domain analogous to that found at the terminus of the $O x$ ytricha complex. The remainder of the telomeric DNA could lie on the outside surface of a multimeric protein complex forming a second nucleoprotein domain of variable length.

\section{Experimental procedures}

\section{Culturing of Oxytricha nova and isolation of macronuclei}

Oxytricha nova was grown in nonsterile culture using live Chlorogonium as the food source (Swanton et al. 1980a). Macronuclei were isolated essentially as described by Swanton et al. (1980a). The following protease inhibitors were included in the isolation buffers: $0.1 \mathrm{~mm}$ phenylmethanesulfonyl fluoride (PMSF), $0.1 \mathrm{~mm}$ tosylphenylalanine chloromethylketone (TPCK), and $1.0 \mathrm{mM}$ p-chloromercuribenzenesulfonic acid (PCMBS).

\section{Methylation protection}

Live Oxytricha in growth media were treated with $5 \mathrm{~mm}$ dimethyl sulfate (DMS) at $25^{\circ} \mathrm{C}$ (Church et al. 1985; Ephrussi et al. 1985). Isolated macronuclei, deproteinized DNA, and reconstituted telomeric complexes were treated with $10 \mathrm{~mm}$ DMS at $25^{\circ} \mathrm{C}$. Unless otherwise stated, DMS treatment was for $10 \mathrm{~min}$. Prior to methylation, macronuclei were suspended in either 10 mM Tris ( $\mathrm{pH} 7.5), 0.5 \%$ Triton $\mathrm{X} 100,0.05 \%$ spermidine, or in $10 \mathrm{~mm}$ Tris (pH 8), $1 \mathrm{~mm}$ EDTA, 0-2 $\mathrm{m} \mathrm{NaCl}$. DMS methylation of DNA and telomeric complexes was performed in 10 mM Tris (pH 8), $1 \mathrm{~mm}$ EDTA, 0-20 mM EGTA. Methylation was stopped by adding $1 / 5$ volume $2.5 \mathrm{M} 2$-mercaptoethanol, $2.5 \%$ SDS. Chromatin from the lysed cells or macronuclei was ethanol-precipitated and the DNA isolated as previously described (Gottschling et al. 1983).

Methylated DNA was $3^{\prime}$-end-labeled using ${ }^{32} \mathrm{P}$-cordycepin and terminal deoxynucleotidyl transferase. The DNA backbone was cleaved at 7-methylguanine adducts by heating in $1 \mathrm{M} \mathrm{pi-}$ peridine at $90^{\circ} \mathrm{C}$ for $30 \mathrm{~min}$ (Maxam and Gilbert 1977, 1980). The cleavage products were analyzed by electrophoresis on sequencing gels.

\section{DNase I digestion of macronuclei}

Macronuclei were suspended in TMS (10 mM Tris, pH 7.5, 10 $\mathrm{mM} \mathrm{MgCl}, 3 \mathrm{mM} \mathrm{CaCl}_{2}, 0.25 \mathrm{M}$ sucrose/ to a final concentration of $3.3 \times 10^{6} / \mathrm{ml}$. Following addition of DNase I, the reaction was incubated at $25^{\circ} \mathrm{C}$ for $10 \mathrm{~min}$. The reaction was stopped by adding EDTA to $50 \mathrm{~mm}$ and SDS to $0.5 \%$ and the DNA isolated.

Isolation, 5'-end-labeling, and DNase I digestion of Oxytricha mononucleosomes

Oxytricha macronuclei suspended in TMS were digested heavily with micrococcal nuclease. Digestion was stopped by the addition of EDTA to $50 \mathrm{~mm}$. Mononucleosomes and dinucleosomes were extracted from the macronuclei by adding $\mathrm{NaCl}$ to $150 \mathrm{~mm}$ and incubating the macronuclei for $1 \mathrm{hr}$ at $4^{\circ} \mathrm{C}$. Mononucleosomes were purified by centrifugation through a $4-22 \%$ sucrose gradient for $16 \mathrm{hr}$ at $36,000 \mathrm{rpm}$ in a Beckman SW41 rotor. Mononucleosome-containing fractions were collected, and the nucleosomes were pelleted by centrifu- gation for $24 \mathrm{hr}$ at $55,000 \mathrm{rpm}$ in a Beckman SW55 rotor (Simpson and Whitlock 1976). The $5^{\prime}$ end of the nucleosomal DNA was radiolabeled using $\left[\gamma^{-32} \mathrm{P}\right] \mathrm{ATP}$ and T4 polynucleotide kinase as described by Lutter (1978). The mononucleosomes were digested with $7 \mathrm{~K}$ units/ml DNase I using the conditions described by Lutter (1979).

\section{Gel electrophoresis and Southern blot analysis}

DNase I-digested DNA was electrophoresed on $6 \%$ denaturing polyacrylamide gels and electrotransferred to the nylon blotting membrane MagnaNylon (MSI Inc.). Transfer was performed as recommended by BioRad (Bulletin 1110). 5'-End-labeling and hybridization of the synthetic oligonucleotide $\left(\mathrm{G}_{4} \mathrm{~T}_{4}\right)_{2}$ were performed as previously described by Gottschling and Cech (1984). High resolution electrophoresis of DNase I-digested DNA was conducted using the gel system described by Lutter (1979). These denaturing gels contained $8 \%$ acrylamide and $1.35 \%$ methylene-bis-acrylamide and were run at $1000-1100 \mathrm{~V}$. The high degree of cross-linking suppresses variation in mobility caused by sequence heterogeneity (Landick et al. 1984), allowing mixed-sequence DNA to be separated solely on the basis of size. Southern blot analysis of high-resolution gels was performed as described above. Electrophoresis of DNA on sequencing gels was performed according to standard procedures (Maniatis et al. 1982).

\section{Isolation of telomere proteins and formation of telomeric DNA-protein complexes}

Telomere proteins were isolated essentially as described by Gottschling and Zakian (1986). Macronuclei were lysed in TE (10 mM Tris (pH 8.0), $1 \mathrm{~mm}$ EDTA) plus $2 \mathrm{M} \mathrm{NaCl}, 0.1 \mathrm{~mm}$ PMSF, $0.1 \mathrm{mM}$ TPCK at $4^{\circ} \mathrm{C}$ for $2 \mathrm{hr}$. The supernatant was applied to a Biogel A $15 \mathrm{M}$ column equilibrated with TE plus $2 \mathrm{M}$ $\mathrm{NaCl}$. DNA-containing fractions were collected and concentrated in Centricon- 10 microconcentrators. The $\mathrm{NaCl}$ concentration was reduced to $<100 \mathrm{mM} \mathrm{NaCl}$ by dilution with TE. TPCK and PMSF were added to the fractions prior to concentration. $\mathrm{CaCl}_{2}$ was added to a concentration of $5 \mathrm{mM}$ and micrococcal nuclease to a concentration of 0.01 units $/ \mu$ l protein preparation, and the telomere proteins were released from the DNA by digestion at $37^{\circ} \mathrm{C}$ for $1 \mathrm{hr}$. The nuclease was inactivated by addition of EGTA to a final concentration of $20 \mathrm{~mm}$.

Telomeric DNA-protein complexes were formed by incubating telomere proteins with DNA at room temperature for 1 hr. The reconstitution mixture consisted of TE plus $20 \mathrm{mM}$ EGTA, $1 \mu \mathrm{g}$ DNA ( 1.4 pmole ends) and 0-4 pmole of each telomere protein per 8-12 $\mu \mathrm{l}$ sample. The molar concentration of the DNA was calculated using $2.2 \mathrm{kbp}$ as the number average molecular weight of Oxytricha nova macronuclear DNA (Swanton et al. 1980b). Protein concentrations were estimated using the assay of Sedmak and Grossberg (1972), with BSA used as the standard. The molar concentration of the telomere proteins was calculated based on the relative abundance of the two proteins in each protein preparation. This was determined by densitometer scanning of SDS gels stained with Coomassie Blue and was found to vary from 0.5 to 3 molecules of $55-\mathrm{kD}$ protein per 1 molecule of $43-\mathrm{kD}$ protein.

Telomere proteins were electrophoresed on $12 \%$ polyacrylamide gels (Laemmli 1970) and stained with Coomassie Brilliant Blue. Immunoblots were performed as previously described (Price et al. 1984).

\section{Acknowledgments}

We thank Dan Gottschling and Virginia Zakian for providing 
antibodies to the $55-\mathrm{kD}$ and $43-\mathrm{kD}$ telomere proteins. This work was supported by NIH grant GM25273 and by a Damon Runyon-Walter Winchell Cancer Fund fellowship, DRG 875, to C.M.P. T.R.C. is an American Cancer Society Research Professor.

\section{References}

Berman, J., C.Y. Tachibana, B.-K. Tye. 1986. Identification of a telomere binding activity from yeast. Proc. Natl. Acad. Sci. 83: $3713-3717$.

Blackburn, E.H. 1984. Telomeres: Do the ends justify the means? Cell 7: 7-8.

Blackburn, E.H. and S.-S. Chiou. 1981. Non-nucleosomal packaging of a tandemly repeated DNA sequence at termini of extrachromosomal DNA coding for rRNA in Tetrahymena. Proc. Natl. Acad. Sci. 78: 2263-2267.

Blackburn, E.H. and J.G. Gall. 1978. A tandemly repeated sequence at the termini of the extrachromosomal ribosomal RNA genes in Tetrahymena. I. Mol. Biol. 120: 33-53.

Blackburn, E.H. and J.W. Szostak. 1984. The molecular structure of centromeres and telomeres. Annu. Rev. Biochem. 53: $163-194$.

Budarf, M.L. and E.H. Blackburn. 1986. Chromatin structure of the telomeric region and 3'-nontranscribed spacer of Tetrahymena ribosomal RNA genes. I. Biol. Chem. 261: 363369.

Butler, A.P., T.J. Laughlin, C.I. Cadilla, J.M. Henry, and D.E. Olins. 1984. Physical structure of gene sized chromatin from the protozoan Oxytricha. Nucleic Acids Res. 12: $3201-3217$.

Campbell, J.L. 1986. Eukaryotic DNA replication. Annu. Rev. Biochem. 55: 733-771.

Cheung, M.K., D.T. Drival, V.C. Littau, and E.M. Johnson. 1981. Protein tightly bound near the termini of the Physarum extrachromosomal rDNA palindrome. I. Cell Biol. 91: 309-314.

Church, G.M., A. Ephrussi, W. Gilbert, and S. Tonegawa. 1985. Cell-type-specific contacts to immunoglobulin enhancers in nuclei. Nature 313: 798-801.

Cockell, M., D. Rhodes, and A. Klug. 1983. Location of the primary sites of micrococcal nuclease cleavage on the nucleosome core. J. Mol. Biol. 170: 423-446.

Dawson, D. and G. Herrick. 1984. Telomeric properties of $\mathrm{C}_{4} \mathrm{~A}_{4}$-homologous sequence in micronuclear DNA of Oxytricha fallax. Cell 36: 171-177.

Ephrussi, A., G.M. Church, S. Tonegawa, and W. Gilbert. 1985. B lineage-specific enhancer with cellular factors in vivo. Science 227: 134-139.

Gilbert, W., A. Maxam, and A. Mirzabekov. 1976. Contacts between the LAC repressor and DNA revealed by methylation. In Control of ribosome synthesis. Alfred Benzon Symp. IX. (ed. N.O. Kjelgaard and O. Maaloe), pp. 139-148. Munksgaard, Copenhagen, Denmark.

Gottschling, D.E. and T.R. Cech. 1984. Chromatin structure of the molecular ends of Oxytricha macronuclear DNA: Phased nucleosomes and a telomeric complex. Cell 38: 501510.

Gottschling, D.E. and V.A. Zakian. 1986. Telomere proteins: Specific recognition and protection of the natural termini of Oxytricha macronuclear DNA. Cell 47: 195-205.

Gottschling, D.E., T.E. Palen, and T.R. Cech. 1983. Different nucleosome spacing in transcribed and non-transcribed regions of the ribosomal RNA gene in Tetrahymena thermophila. Nucleic Acids Res. 11: 2093-2109.

Greider, C.W. and E.H. Blackburn. 1985. Identification of a spe- cific telomere terminal transferase activity in Tetrahymena extracts. Cell 43: 405-413.

Johnson, B.H. and A. Rich. 1985. Chemical probes of DNA conformation: Detection of Z-DNA at nucleotide resolution. Cell 42: 713-724.

Klobutcher, L.A., M.T. Swanton, P. Donini, and D.M. Prescott. 1981. All gene-sized DNA molecules in four species of hypotrichs have the same terminal sequence and an unusual 3' terminus. Proc. Natl. Acad. Sci. 78: 3015-3019.

Klobutcher, L.A., C.L. Jahn, and D.M. Prescott. 1984. Internal sequences are eliminated from genes during macronuclear development in the ciliated protozoan Oxytricha nova. Cell 36: 1045-1055.

Klug, A. and L.C. Lutter. 1981. The helical periodicity of DNA on the nucleosome. Nucleic Acids Res. 9: 4267-4283.

Laemmli, U.K. 1970. Cleavage of structural proteins during the assembly of bacteriophage T4. Nature 227: 680-685.

Landick, R., D. Maguire, and L.C. Lutter. 1984. Optimization of polyacrylamide gel electrophoresis conditions used for sequencing mixed oligodeoxyribonucleotides. DNA 3: 413419.

Lawn, R.M., J.M. Heumann, G. Herrick, and D.M. Prescott. 1977. The gene-size DNA molecules in Oxytricha. Cold Spring Harbor Symp. Quant. Biol. 42: 483-492.

Lipps, H.J., W. Gruissem, and D.M. Prescott. 1982. Higher order DNA structure in macronuclear chromatin of the hypotrichous ciliate Oxytricha nova. Proc. Natl. Acad. Sci. 79: 2495-2499.

Liu, L.F. and J.C. Wang. 1978. DNA-DNA gyrase complex: The wrapping of the DNA duplex outside the enzyme. Cell 15: $979-984$.

Lohman, T.M. and L.B. Overman. 1985. Two binding modes in Escherichia coli single strand binding protein-single stranded DNA complexes. J. Biol. Chem. 260: 3594-3603.

Lutter, L.C. 1978. Kinetic analysis of deoxyribonuclease I cleavages in the nucleosome core: Evidence for a DNA superhelix. J. Mol. Biol. 124: 391-420.

-1979. Precise location of DNase I cutting sites in the nucleosome core determined by high resolution gel electrophoresis. Nucleic Acids Res. 6: 41-56.

Maniatis, T., E. Fritsch, and J. Sambrook. 1982. Molecular cloning: A laboratory manual. Cold Spring Harbor Laboratory, Cold Spring Harbor, New York.

Maxam, A. and W. Gilbert. 1977. A new method for sequencing DNA. Proc. Natl. Acad. Sci. 74: 560-564.

.1980. Sequencing of end-labeled DNA with base-specific chemical cleavages. Methods Enzymol. 65: 499-560.

Noll, M. 1974. Internal structure of the chromatin subunit. $\mathrm{Nu}$ cleic Acids Res. 1: 1573-1587.

Prescott, D.M. 1983. The C-value paradox and genes in ciliated protozoa. Mod. Cell Biol. 2: 329-352.

Price, C.M., G. McCarty, and D.E. Pettijohn. 1984. NuMA protein is a human autoantigen. Arthritis Rheum. 27: 775-779.

Prunell, A., R.D. Kornberg, A. Klug, M. Levitt, and F.H.C. Crick. 1979. Periodicity of deoxyribonuclease I digestion of chromatin. Science 204: 855-858.

Rhodes, D. 1985. Structural analysis of a triple complex between the histone octamer, a Xenopus gene for 5S RNA and transcription factor IIIA. EMBO $\%$. 4: 3473-3482.

Rhodes, D. and A. Klug. 1980. Helical periodicity of DNA determined by enzyme digestion. Nature 286: 573-578.

Ribas-Aparicio, R.M., J.J. Sparkowski, A.E. Proulx, J.J. Mitchell, and L.A. Klobutcher. 1987. Nucleic acid splicing events occur frequently during macronuclear development in the protozoan Oxytricha nova and involve the elimination of unique DNA. Genes Dev. 1: 323-336.

Richmond, T.J., J.T. Finch, B. Rushton, D. Rhodes, and A. Klug. 
1984. Structure of the nucleosome core particle at $7 \AA$ resolution. Nature 311: 532-537.

Sedmak, J.J. and S.E. Grossberg. 1972. A rapid sensitive and versatile assay for protein using Coomassie Brilliant Blue G 250. Anal. Biochem. 79: 544-552.

Siebenlist, U. and W. Gilbert. 1980. Contacts between Escherichia coli RNA polymerase and an early promotor of phage T7. Proc. Natl. Acad. Sci. 77: 122-126.

Simpson, R.T. and D.W. Stafford. 1983. Structural features of a phased nucleosome core particle. Proc. Natl. Acad. Sci. 80: $51-55$.

Simpson, R.T. and J.P. Whitlock. 1976. Mapping DNase I-susceptible sites in nucleosomes labeled at the $5^{\prime}$ ends. Cell 9: $347-353$.

Simpson, R.T., F. Thoma, and J.M. Brubaker. 1985. Chromatin reconstituted from tandemly repeated cloned DNA fragments and core histones: A model system for study of higher order structure. Cell 42: 799-808.

Swanton, M.T., A.F. Greslin, and D.M. Prescott. 1980a. Arrangement of coding and non-coding sequences in the DNA molecules for rRNAs in Oxytricha sp. Chromosoma 77: 203-215.

Swanton, M.T., J.M. Heumann, and D.M. Prescott. 1980b. Gene-sized DNA molecules of the macronuclei in three species of hypotrichs: Size distribution and absence of nicks. Chromosoma 77: 217-227.

Yao, M.-C. and C.-H. Yao. 1981. Repeated hexanucleotide C-C-C-C-A-A is present near free ends of macronuclear DNA of Tetrahymena. Proc. Natl. Acad. Sci. 78: 74367439. 


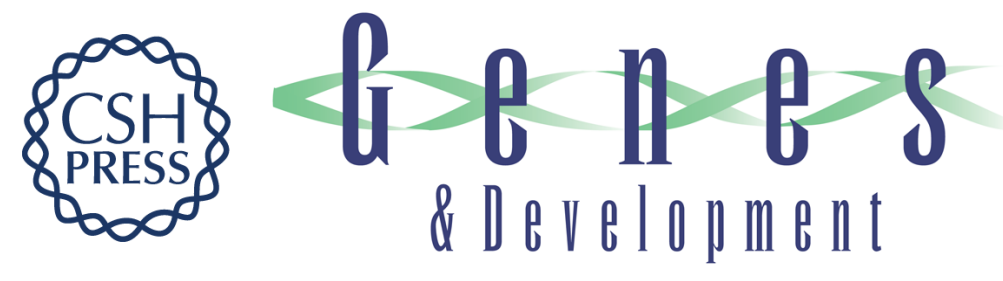

\section{Telomeric DNA-protein interactions of Oxytricha macronuclear DNA.}

C M Price and T R Cech

Genes Dev. 1987, 1:

Access the most recent version at doi:10.1101/gad.1.8.783

References This article cites 47 articles, 14 of which can be accessed free at:

http://genesdev.cshlp.org/content/1/8/783.full.html\#ref-list-1

License

Email Alerting Receive free email alerts when new articles cite this article - sign up in the box at the top Service right corner of the article or click here.

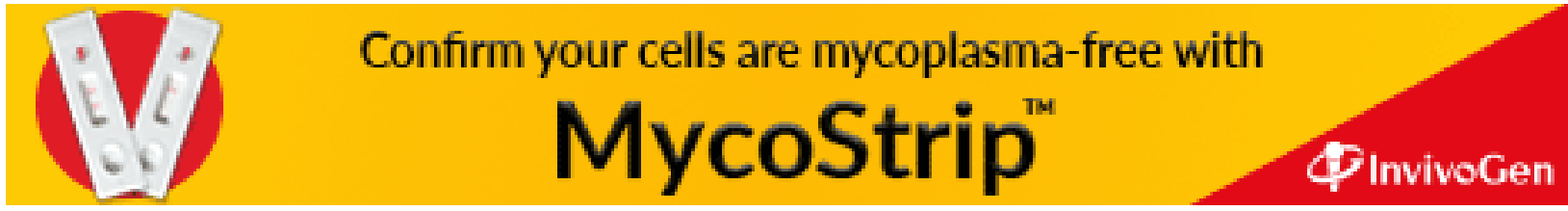

